\title{
Penerapan Algoritma Apriori Untuk Mempercepat dan Mempermudah Akses Barang di Gudang Material (Studi Kasus pada PT.XYZ)
}

\author{
Arwin Datumaya Wahyudi Sumari ${ }^{1,4}$, Maulana Zinedin Zidane ${ }^{2}$, Odhitya Desta Triswidrananta ${ }^{3}$
}

${ }^{1}$ Cognitive Artificial Intelligence Research Group (CAIRG), Jurusan Teknik Elektro, Politeknik Negeri Malang

${ }^{2,3}$ Program Studi Teknik Informatika, Jurusan Teknologi Informasi, Politeknik Negeri Malang

${ }^{4}$ Program Studi Teknologi Persenjataan, Fakultas Teknologi Pertahanan, Universitas Pertahanan

1arwin.sumari@polinema.ac.id, ${ }^{2}$ maulanazinedinzidane@gmail.com, ${ }^{3}$ odhitya.desta@ polinema.ac.id

\begin{abstract}
Abstrak
Pada sebuah gudang material dengan beragam jenis barang dalam jumlah besar, menemukan satu barang atau kombinasi beberapa barang sesuai permintaan menjadi sebuah tantangan yang perlu diberikan solusi. Kecepatan dan kemudahan akses barang merupakan parameter-parameter penting yang membantu petugas gudang dalam memperoleh barang-barang sesuai yang diminta. Dalam penelitian ini telah dibangun sebuah sistem pemberi rekomendasi penataan barang atau kombinasi beberapa barang pada rak-rak di dalam gudang material menggunakan algoritma apriori. Studi kasus menggunakan data transaksi barang di gudang material PT. XYZ dengan beberapa kombinasi barang sesuai dengan kondisi riil. Dari penelitian ini diperoleh hasil bahwa sistem perekomendasi akan memberikan hasil penataan barang atau kombinasi beberapa barang yang optimal bila menggunakan nilai minimum support $2 \%$ yang mana akan diperoleh frequent 1-itemset sebanyak 55 itemset dan frequent 2-itemset sebanyak 26 itemset. Dari pengujian pada frequent 2-itemset diperoleh bahwa kombinasi terbaik adalah nilai minimum support $2 \%$ dan nilai minimum confidence $40 \%$ yang menghasilkan 42 aturan asosiasi pada kombinasi 2 macam barang yang sering diambil secara bersamaan. Untuk rekomendasi penentuan lokasi barang didasarkan nilai lift ratio (LR) dari setiap kombinasi barang. Penataan ulang lokasi barang-barang berdasarkan nilai LR telah mampu mereduksi jarak antara meja petugas dengan lokasi barang hingga rerata $77 \%$ sehingga meningkatkan kecepatan pengambilan barang rerata 79\%. Menggunakan parameter support, confidence, dan LR secara bersama telah mampu meningkatkan kepresisian penentuan lokasi barang-barang dalam gudang material.
\end{abstract}

Kata kunci : algoritma apriori, frequent itemset, gudang material, lift rasio, tata ulang lokasi barang

\section{Pendahuluan}

Pada era globalisasi saat ini, tingkat persaingan di berbagai bidang usaha semakin meningkat. Keadaan ini mendorong para pemain di bidang usaha untuk melakukan penyesuaian dengan menyusun strategi usaha agar dapat memenangkan persaingan usaha. Strategi yang diterapkan diharapkan dapat menjadikan perusahaan beroperasi secara efisien agar dapat meningkatkan daya saing. Efisiensi dapat dilakukan pada banyak aspek, diantaranya adalah mereduksi semaksimal mungkin biaya layanan kepada konsumen. Salah satu biaya layanan tersebut adalah waktu tunggu antara permintaan dan penerimaan barang yang diambilkan dari gudang.

Gudang adalah bagian terpenting dari satu proses produksi dan berfungsi sebagai tempat penyimpanan material produksi, di samping manajemen gudang untuk mengatur dengan baik aliran barang. Tata letak barang di dalam gudang memiliki peran penting karena memberi dampak strategis kepada perusahaan pada aspek diantaranya kapasitas, aliran material, fleksibilitas, biaya, dana kualitas lingkungan kerja. Tata letak gudang juga diperlukan guna memudahkan pengambilan barang serta penataan barang yang akan disimpan, Rahardjo, (2017). Dengan pengaturan tata letak gudang yang baik dan rapi, maka produktivitas perusahaan akan meningkat, Aristanto (2017).

Salah satu perusahaan yang memanfaatkan manajemen pergudangan adalah PT. XYZ di Kota Malang. Perusahaan ini bergerak di bidang industri gula dan memiliki unit Gudang yang menyimpan beragam barang material kebutuhan pabrik para rakraknya. Penyusunan beragam jenis barang material yang belum tertata rapi memberikan kesulitan bagi petugas gudang ketika mengambil barang material yang diminta. Lebih lagi penataan barang material yang masih belum berdasarkan pada jenis barang material atau kombinasi dari jenis-jenis barang tertentu yang sering diambil, juga menjadikan biaya layanan tinggi ditinjau dari aspek kecepatan dan kemudahan memperoleh barang atau kombinasi barang.

Memperhatikan hal di atas, diperlukan satu cara untuk membantu pegawai gudang dalam menata barang-barang material pada rak-rak yang bersesuaian guna meningkatkan kecepatan akses barang-barang material ditinjau dari permintaan 
barang, pengambilan barang, hingga penerimaan barang kepada konsumen. Berdasarkan pada permasalahan tersebut, disusun sebuah hipotesis bahwa dengan melakukan penataan barang-barang material di gudang menggunakan algoritma apriori maka akan dapat meningkatkan kecepatan dan kemudahan memperoleh barang material atau kombinasi beberapa barang material sesuai permintaan. Konsep yang dibangun dalam penelitian ini adalah memanfaatkan satu teknik dalam data mining yakni algoritma apriori sebagai pemberi rekomendasi penataan barang-barang material berdasarkan pada frekuensi barang yang sering diambil pada transaksi atau barang keluar dengan memperhitungkan kapasitas rak dan rasio angkat (lift ratio) tertinggi terhadap barang yang sering diambil. Hasil lokasi penataan barang material yang dihasilkan oleh sistem digunakan hanya sebatas rekomendasi.

\section{Tinjauan Pustaka \\ 2.1 Data Mining}

Data mining adalah satu istilah yang digunakan untuk menguraikan penemuan pengetahuan di dalam basis data (database) menggunakan Teknik-teknik statistik, matematika, kecerdasan artifisial (artificial intelligence), dan machine learning. Data mining juga dapat diartikan sebagai pengekstrakan informasi baru yang diambil dari bongkahan data besar yang membantu dalam pengambilan keputusan. Data mining sering juga disebut Knowledge Discovery in Database (KDD), yakni kegiatan yang meliputi pengumpulan, pemakaian data historis untuk menemukan keteraturan, pola atau hubungan dalam himpunan data yang berukuran besar, Santoso (2017).

Salah satu teknik dalam data mining adalah aturan asosiasi (association rule) pada algoritma apriori, Mandave, Mane, \& Patil (2013). Dalam aturan asosiasi, terdapat dua bagian yakni anteseden (antecedent) yang diwakili dengan "if", dan konsekuen (consequent) yang direpresentasikan dengan "then". Relasi antara anteseden dan konsekuen direpresentasikan dengan tanda “ $\rightarrow$ ". Jika anteseden menyatakan adanya sebuah itemset di dalam data, maka konsekuen menyatakan adanya sebuah itemset bersama dengan anteseden, Singh \& Chaudhary (2012).

\subsection{Algoritma Apriori}

Algoritma apriori adalah algoritma yang dapat digunakan untuk mencari aturan-aturan asosiasi yang memenuhi batas support dan confidence. Pencarian aturan asosiasi harus menggunakan parameterparameter tertentu sehingga aturan yang didapat akurat. Parameter-parameter yang digunakan untuk pembentukan aturan-aturan (rule) yaitu:

a) Support
Support adalah ukuran yang menunjukkan seberapa besar tingkat dominasi satu atau lebih barang, disebut dengan itemset dari keseluruhan transaksi. Bila terdapat dua barang, A sebagai anteseden dan B sebagai konsekuen, maka support merupakan persentase minimum dari transaksi yang mengandung itemset, $\mathrm{A}$ dan $\mathrm{B}$ atau $A \cup B$, dalam basis data, Mandave, Mane, \& Patil (2018). Besarnya persentase support untuk 1 itemset dan 2 itemset diperlihatkan pada Persamaan (1) dan Persamaan (2), dimana $N_{T A}$ adalah jumlah transaksi mengandung barang A dan $N_{T o t}$ adalah jumlah total transaksi serta $N_{T A \cup B}$ adalah jumlah transaksi mengandung itemset barang A dan B.

$$
\begin{gathered}
\text { Support }(A)=\frac{N_{T A}}{N_{T o t}} \\
\text { Support }(A \cup B)=\frac{N_{T A \cup B}}{N_{T o t}}
\end{gathered}
$$

\section{b) Confidence}

Confidence adalah satu ukuran yang menunjukkan hubungan kondisional antar dua barang (misal: seberapa sering barang B dibeli jika orang membeli barang A) yang dihitung menggunakan Persamaan (3). Untuk menghitung nilai persentase confidence menggunakan Persamaan (4).

$$
\begin{aligned}
\text { Confidence }(A \rightarrow B) & =\frac{N_{T A \cup B}}{N_{T A}} \\
& =\frac{\text { Support }(A \cup B)}{\text { Support A }} \\
\text { Confidence }(A \rightarrow B) & =\frac{\text { Support }(A \cup B)}{\text { Support A }} x 100
\end{aligned}
$$

Terdapat dua proses utama dalam algoritma apriori yaitu:

1) Penggabungan (join). Dalam proses ini, setiap itemset dikombinasikan dengan itemset lain sampai tidak dapat terbentuk kombinasi lagi.

2) Pemangkasan (pruning). Pada proses ini, hasil kombinasi itemset akan dipangkas berdasarkan support minimum yang telah ditentukan (Yuliana et al., 2018).

\section{c) Lift Ratio}

Lift Ratio (LR) mengukur seberapa penting rule yang telah terbentuk berdasarkan nilai support dan confidence dan menjadi landasan bahwa aturan yang dibuat dapat menjadi dasar rekomendasi, Riszky \& Sadikin (2019). LR merupakan nilai yang menunjukkan validitas proses transaksi dan memberikan informasi apakah benar barang A dibeli bersamaan dengan barang B. LR digunakan untuk mengevaluasi kekuatan sebuah aturan asosiasi yang didapatkan melalui perbandingan antara nilai confidence dengan nilai benchmark confidence. Benchmark confidence adalah jumlah perbandingan 
semua itemset yang menjadi consequent terhadap total jumlah transaksi.

Apabila $L R>1$, maka menunjukkan adanya manfaat dari aturan tersebut. Nilai LR makin tinggi menunjukkan kekuatan asosiasi yang lebih besar. Bila $N_{C}$ adalah jumlah transaksi itemset konsekuen, Riszky \& Sadikin (2019) maka Benchmark confidence diperoleh dengan menggunakan Persamaan (5) sedangkan menghitung LR diperoleh dengan menggunakan Persamaan (6), Zahrotun, Setiadi, \& Haryadi (2018).

$$
\begin{gathered}
\text { Benchmark confidence }(A \cup B)=\frac{N_{C}}{N_{T o t}} \\
\text { Lift Ratio }=\frac{\text { Confidence }(A \cup B)}{\text { Benchmark confidence }(A \cup B)}
\end{gathered}
$$

\subsection{Itemset dan Minimum Support}

Itemset adalah satu himpunan barang, dan sebuah itemset yang terdiri dari $\mathrm{n}$ barang disebut dengan $\mathrm{n}$ itemset dimana $n>0$. Kinerja satu sistem berbasis algoritma apriori dalam memberikan rekomendasi penataan barang dapat diketahui dari itemset yang paling sering diambil (frequent itemset) ditinjau dari aturan minimum support. Pada penelitian ini akan dilakukan pengujian dengan mengatur nilai minimum support untuk mengetahui pembentukan itemset untuk 1-itemset dan 2-itemset.

Minimum support atau support dari satu pola asosiasi adalah persentase yang memperlihatkan kebenaran pola dari transaksi barang, Han \& Kamber (2013). Maka sebuah itemset disebut dengan frequent bila ia memenuhi minimum support atau lebih. Minimum support digunakan untuk menunjukkan seberapa besar tingkat dominasi satu barang atau itemset dari keseluruhan transaksi.

\section{Metodologi Penelitian \\ 3.1 Metode Pengumpulan Data}

Dalam penelitian ini ada metode pengambilan data yakni :

a) Observasi. Kegiatan ini dilakukan dengan pengamatan langsung ke lapangan untuk memperoleh data primer transaksi barangbarang material yang dilakukan di gudang PT. $\mathrm{XYZ}$.

b) Wawancara. Kegiatan ini dilakukan dengan mewawancarai para pegawai gudang untuk memperoleh data primer mengenai tata cara mereka melakukan penataan barang-barang material di dalam gudang.

\subsection{Data}

Data yang digunakan merupakan data primer berupa transaksi barang-barang material sebanyak 1.381 kali pada rentang waktu selama 2 bulan. Datadata transaksi dikelompokkan menjadi data harian berdasarkan tanggal transaksi barang-barang material tersebut. Sampel data transaksi diperlihatkan pada Tabel 1, sedangkan representasi transaksi dalam format tabular diperlihatkan pada Tabel 2.

Format tabular diperoleh dari konversi terjadinya transaksi pada setiap barang. Bila pada transaksi ke- $i$ terdapat barang $j$ yang diambil, maka pada lokasi baris-kolom pertemuan transaksi $i$ dan barang $j$, akan diberi kode biner ' 1 ', dan demikian pula bila sebaliknya akan diberi kode biner ' 0 ', Buulolo (2013).

Tabel 1 Sampel Data Transaksi

\begin{tabular}{|c|l|}
\hline No. & \multicolumn{1}{|c|}{ Barang yang diambil } \\
\hline 1. & $\begin{array}{l}\text { Mur Baut Metric M 12 X 50, Obeng, Sepatu } \\
\text { Proyek, Ring Plat 1/2" }\end{array}$ \\
\hline 2. & $\begin{array}{l}\text { Kunci Inggris 10 In, Baut Cis 3/16" X 1 1/2", } \\
\text { Oil Seal 50mm X 72mm X 12 Mm }\end{array}$ \\
\hline 3. & $\begin{array}{l}\text { Cat Tembok, Oil Seal 50mm X 72mm X 12 Mm, } \\
\text { Baut Cis 3/16" X 1 1/2" }\end{array}$ \\
\hline 4. & $\begin{array}{l}\text { Oil Seal 80 X 100 X 13 Mm, Baut Seng 1/4" X } \\
\text { 3/4", Welding Apron Leather, Kertas Gosok No } \\
\text { 0/1 }\end{array}$ \\
\hline 5. & $\begin{array}{l}\text { Cat Tembok, Kwas Cat 4", Piston Ring } \\
\text { Vercroom 102-1006, Mur Baut Metric M 10 X } \\
50\end{array}$ \\
\hline 6. & $\begin{array}{l}\text { Seal Rubber Rectangular, Oil Seal 50mm X } \\
72 m m \text { X 12 Mm, Treaded End \& Nuts 1/2", Oil } \\
\text { Seal 55 X 72 X 9 }\end{array}$ \\
\hline 7. & $\begin{array}{l}\text { Baut Cis 3/16" X 1 1/2", Sapu Ijuk, Oil Seal } \\
50 m m \text { X 72mm X 12 Mm }\end{array}$ \\
\hline 8. & $\begin{array}{l}\text { Cutter, Piston Ring Vercroom 102-1006, Sarung } \\
\text { Tangan, Mur Baut 1/4" X 3/4" }\end{array}$ \\
\hline
\end{tabular}

Tabel 2 Format Tabular Transaksi

\begin{tabular}{|l|c|c|c|c|c|c|c|c|}
\hline \multirow{2}{*}{ Barang } & \multicolumn{6}{|c|}{ Transaksi Tanggal 1/02/2020 } \\
\cline { 2 - 9 } & $\mathbf{1}$ & $\mathbf{2}$ & $\mathbf{3}$ & $\mathbf{4}$ & $\mathbf{5}$ & $\mathbf{6}$ & $\mathbf{7}$ & $\mathbf{8}$ \\
\hline Baut Cis 3/16" X 1 1/2" & 0 & 1 & 1 & 0 & 0 & 0 & 1 & 0 \\
\hline Baut Seng 1/4" X 3/4" & 0 & 0 & 0 & 1 & 0 & 0 & 0 & 0 \\
\hline Cat Tembok & 0 & 0 & 1 & 0 & 1 & 0 & 0 & 0 \\
\hline Cutter & 0 & 0 & 0 & 0 & 0 & 0 & 0 & 1 \\
\hline Kertas Gosok No. 0/1 & 0 & 0 & 0 & 1 & 0 & 0 & 0 & 0 \\
\hline Kunci Inggris 10 In & 0 & 1 & 0 & 0 & 0 & 0 & 0 & 0 \\
\hline Kwas Cat 4" & 0 & 0 & 0 & 0 & 1 & 0 & 0 & 0 \\
\hline Mur Baut 1/4" X 3/4" & 0 & 0 & 0 & 0 & 0 & 0 & 0 & 1 \\
\hline Mur Baut Metric M 10 X 50 & 0 & 0 & 0 & 0 & 1 & 0 & 0 & 0 \\
\hline Mur Baut Metric M 12 X 50 & 1 & 0 & 0 & 0 & 0 & 0 & 0 & 0 \\
\hline Obeng & 1 & 0 & 0 & 0 & 0 & 0 & 0 & 0 \\
\hline Oil Seal 50mm X 72mm X & 0 & 1 & 1 & 0 & 0 & 1 & 1 & 0 \\
12 Mm & & & & & & & & \\
\hline Oil Seal 55 X 72 X 9 & 0 & 0 & 0 & 0 & 0 & 1 & 0 & 0 \\
\hline Oil Seal 80 X 100 X 13 Mm & 0 & 0 & 0 & 1 & 0 & 0 & 0 & 0 \\
\hline $\begin{array}{l}\text { Piston Ring Vercroom } \\
\text { 102-1006 }\end{array}$ & 0 & 0 & 0 & 0 & 1 & 0 & 0 & 1 \\
\hline Ring Plat 1/2" & & & & & & & & \\
\hline Sapu Ijuk & 1 & 0 & 0 & 0 & 0 & 0 & 0 & 0 \\
\hline Sarung Tangan & 0 & 0 & 0 & 0 & 0 & 0 & 1 & 0 \\
\hline Seal Rubber Rectangular & 0 & 0 & 0 & 0 & 0 & 0 & 0 & 1 \\
\hline Sepatu Proyek & 0 & 0 & 0 & 0 & 0 & 1 & 0 & 0 \\
\hline Treaded End \& Nuts 1/2" & 1 & 0 & 0 & 0 & 0 & 0 & 0 & 0 \\
\hline Welding Apron Leather & 0 & 0 & 0 & 0 & 0 & 1 & 0 & 0 \\
\hline
\end{tabular}

\subsection{Perancangan Sistem}


a) Diagram Alir Sistem

Dalam hal ini diagram alir (flowchart) sebagaimana diperlihatkan pada Gambar 1, digunakan untuk memperlihatkan aliran pengolahan data menggunakan algoritma apriori. Tahapan dimulai dengan memasukkan data barang (itemset), data transaksi, dan data lokasi. Selanjutnya sistem akan melakukan pencarian calon kombinasi barang sesuai dengan transaksi atau pembentukan itemset. Bila pembentukan itemset berhasil, maka akan diperoleh luaran berupa barang-barang yang sesuai dengan frekuensi pengambilan dan lokasi barang. Sebaliknya jika gagal, maka tahapan akan kembali ke proses pembentukan itemset.

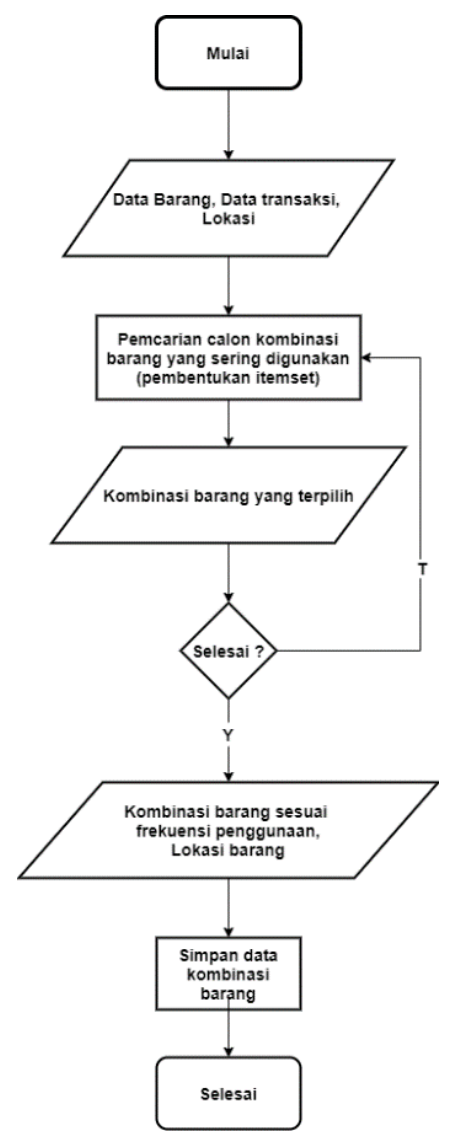

Gambar 1 Diagram alir algoritma apriori.

\section{b) Usecase Diagram}

Usecase menggambarkan fungsionalitas satu system agar pengguna (user) mengerti mengenai aplikasi yang akan dibangun, Nanda \& Saleh (2017). Pada sistem yang dirancang ini terdapat dua aktor yaitu kepala gudang atau admin, dan pegawai gudang. Kepala gudang dapat mengakses semua menu yang disediakan oleh sistem seperti mengelola data barang, data lokasi, data stok, data transaksi pengambilan, cetak laporan dengan format Portable Document Format (PDF) atau Excel, dan mengatur nilai support dan nilai confidence untuk menentukan lokasi barang sesuai frekuensi pengambilan barang. Di sisi lain, pegawai gudang hanya dapat mengakses menu transaksi dan melihat hasil algoritma apriori untuk menentukan lokasi barang. Usecase diagram sistem diperlihatkan pada Gambar 2.

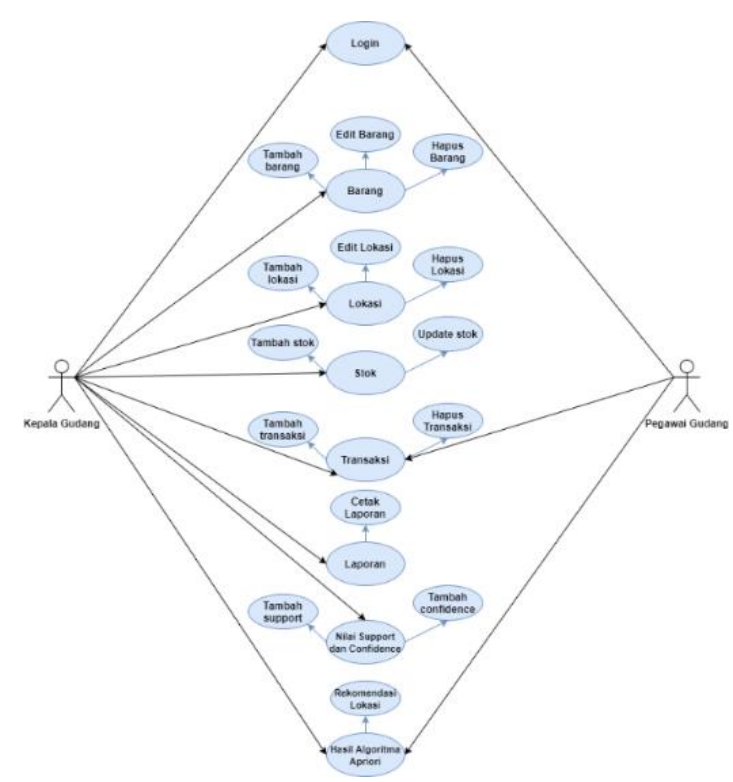

Gambar 2 Usecase diagram sistem rekomendasi berbasis algoritma apriori.

\section{c) Data Flow Diagram (DFD) dan Entity \\ Relationship Diagram (ERD)}

DFD sistem yang menggambarkan aliran data menggunakan algoritma apriori diperlihatkan pada Gambar 3 dan Gambar 4, sedangkan ERD yang memperlihatkan hubungan antar data pada basis data yang mempunyai hubungan antar relasi diperlihatkan pada Gambar 5.

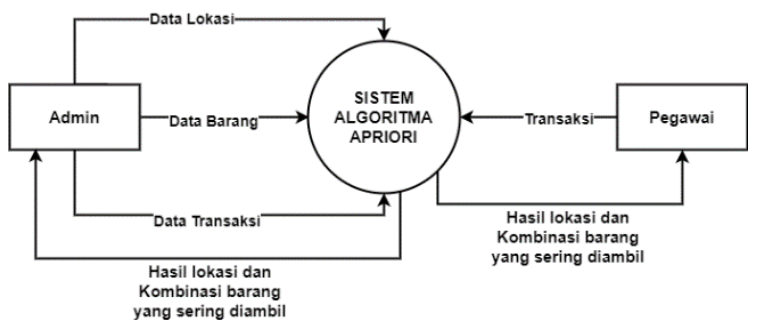

Gambar 3 DFD Level 0 algoritma apriori.

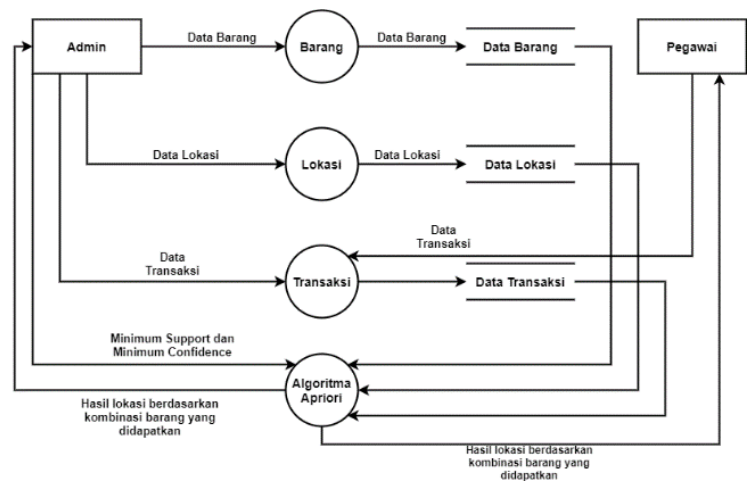

Gambar 4 DFD Level 1 algoritma apriori. 


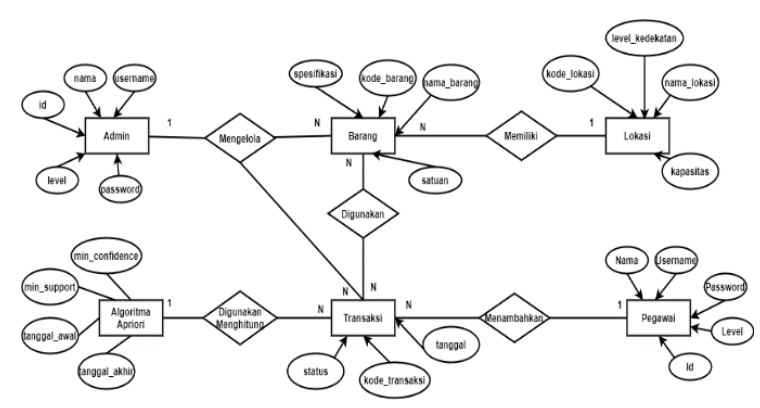

Gambar 5 ERD algoritma apriori.

\section{Hasil dan Analisa}

\subsection{Hasil-Hasil Penerapan Algoritma Apriori}

Pada penelitian ini dilakukan 4 macam pengujian yakni: 1) pengujian untuk mengetahui dampak nilai minimum support pada pembentukan itemset, 2) dampak nilai minimum support pada pembentukan aturan bila digabungkan dengan nilai minimum confidence dengan 4 nilai minimum support yakni $2 \%, 3 \%$, 4\%, dan 5\%, dan 3) pengujian kekuatan aturan asosiasi yang dibentuk serta 4) penentuan lokasi barang berdasarkan LR dan confidence.

a) Pengaruh Nilai Minimum Support pada Frequent 1-itemset dan 2-itemset

Hasil-hasil pengujian variasi nilai minimum support untuk pembentukan 1-itemset disampaikan pada Tabel 3 dan Gambar 6. Hasil-hasil pengujian variasi nilai minimum support untuk pembentukan 2itemset disampaikan pada Tabel 4 dan Gambar 7.

Tabel 3 Hasil Uji pada Frequent 1-Itemset

\begin{tabular}{|c|c|}
\hline Minimum Support & 1-Itemset \\
\hline $2 \%$ & 55 \\
\hline $3 \%$ & 33 \\
\hline $4 \%$ & 28 \\
\hline $5 \%$ & 23 \\
\hline
\end{tabular}

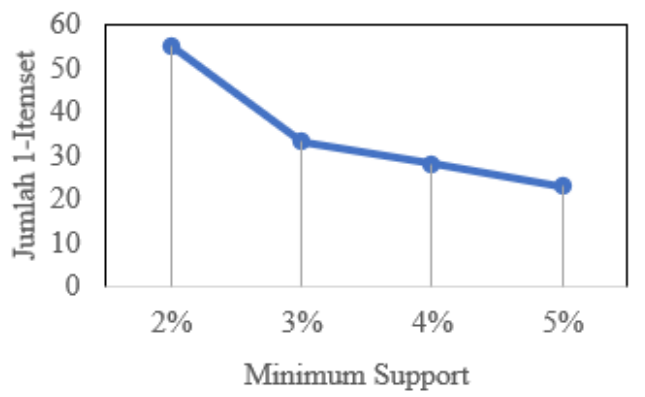

Gambar 6 Pengaruh nilai minimum support pada jumlah frequent 1-Itemset.

Tabel 3 dan Gambar 4 memperlihatkan bahwa semakin tinggi nilai minimum support, maka semakin sedikit jumlah baik frequent 1-itemset maupun 2itemset. Dengan kata lain, pembentukan 1-itemset dan 2-itemset semakin berkurang dengan bertambahnya nilai minimum support. Pembentukan 1-itemset dan 2-itemset mengalami penurunan signifikan pada perubahan nilai minimum support dari $2 \%$ ke $3 \%$.

Tabel 4 Hasil Uji pada Frequent 2-Itemset

\begin{tabular}{|c|c|}
\hline Minimum Support & 2-Itemset \\
\hline $2 \%$ & 26 \\
\hline $3 \%$ & 10 \\
\hline $4 \%$ & 3 \\
\hline $5 \%$ & 1 \\
\hline
\end{tabular}

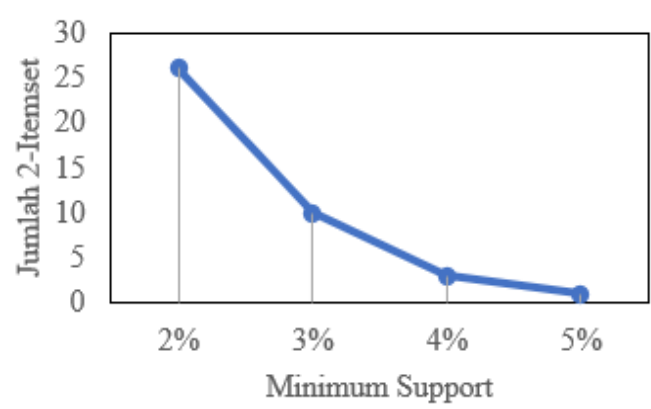

Gambar 7 Pengaruh nilai minimum support pada jumlah frequent 2-Itemset.

b) Pengaruh Nilai Minimum Support dan Minimum Confidence pada Pembentukan Aturan

Pada penelitian ini digunakan nilai minimum confidence $40 \%$ dan $50 \%$ untuk frequent 2-itemset. Nilai confidence digunakan untuk menunjukkan hubungan kondisional antar dua barang. Pengaruh nilai minimum support dan nilai minimum confidence terhadap pembentukan aturan diperlihatkan pada Tabel 5 dan Gambar 8. Dari pengujian ini diperoleh hasil bahwa banyaknya kombinasi frequent itemset ditentukan oleh kombinasi nilai minimum support dan nilai minimum confidence. Pada kasus 2-itemset, aturan asosiasi terbanyak yakni 42 aturan diperoleh dari kombinasi minimum support $2 \%$ dan minimum confidence $40 \%$. Semakin banyak aturan maka semakin lengkap frequent itemset sehingga barangbarang yang diambil diharapkan akan makin sesuai dengan permintaan.

Tabel 5 Pengaruh Minimum Support dan Minimum Confidence pada Pembentukan Aturan

\begin{tabular}{|c|c|c|}
\hline $\begin{array}{c}\text { Minimum } \\
\text { Support }\end{array}$ & $\begin{array}{c}\text { Minimum } \\
\text { Confidence }\end{array}$ & Aturan \\
\hline $2 \%$ & $40 \%$ & 42 \\
\hline $2 \%$ & $50 \%$ & 28 \\
\hline $3 \%$ & $40 \%$ & 20 \\
\hline $3 \%$ & $50 \%$ & 15 \\
\hline $4 \%$ & $40 \%$ & 6 \\
\hline $4 \%$ & $50 \%$ & 6 \\
\hline $5 \%$ & $40 \%$ & 2 \\
\hline $5 \%$ & $50 \%$ & 2 \\
\hline
\end{tabular}


Pada Gambar 8 dapat disimpulkan bahwa semakin besar nilai minimum support dan nilai minimum confidence yang digunakan, maka aturan yang terbentuk akan berkurang. Sebaliknya bila nilai minimum support dan nilai minimum confidence semakin kecil, maka aturan yang terbentuk akan semakin banyak. Hal ini selaras dengan jumlah frequent itemset yang dibentuk melalui nilai minimum support.

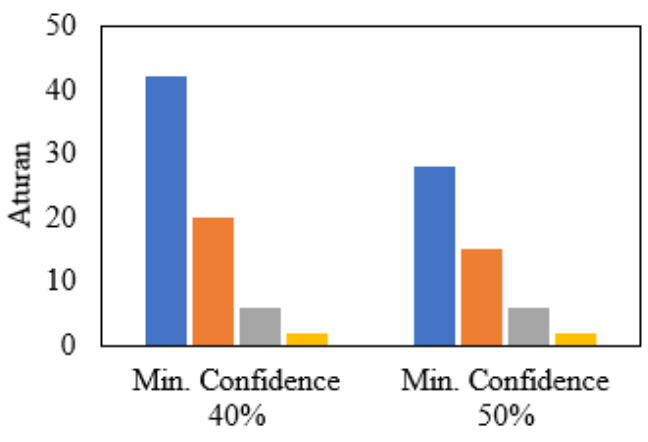

- Min. Support 2\% = Min Support 3\%

$\varpi$ Min. Support 4\% $₫$ Min. Support 5\%

Gambar 8 Perbandingan pengaruh minimum support dan minimum confidence pada pembentukan aturan.

c) Pengujian Kekuatan Aturan Asosiasi

Pengujian kekuatan 42 aturan asosiasi pada frequent 2-itemset pada Tabel 6. Dari hasil komputasi menggunakan Persamaan (6) diperoleh hasil bahwa LR terendah diperoleh oleh aturan asosiasi ke-4 dan ke-5 dengan nilai 5,95. Nilai LR terbesar diperoleh oleh aturan asosiasi ke-29 dan ke-30 dengan nilai 23,68. Dengan demikian dapat diperoleh hasil bahwa nilai LR dari 42 aturan asosiasi telah memenuhi syarat yakni $L R>1$.

Tabel 6 Hasil Pengujian LR

\begin{tabular}{|c|c|c|c|}
\hline $\begin{array}{l}\text { Atu- } \\
\text { ran } \\
\text { ke- }\end{array}$ & Aturan Asosiasi & $\begin{array}{l}\text { Confi- } \\
\text { dence }\end{array}$ & LR \\
\hline$\ldots$ & $\cdots$ & $\ldots$ & $\ldots$ \\
\hline 4 & $\begin{array}{l}\text { Jika Mengambil Oil Seal } 55 \\
\text { X } 72 \text { X } 9 \text { maka akan } \\
\text { mengambil Oil Seal 50mm } \\
\text { X } 72 \mathrm{~mm} \text { X } 12 \mathrm{Mm}\end{array}$ & $42,27 \%$ & 5,95 \\
\hline 5 & $\begin{array}{l}\text { Jika Mengambil Oil Seal } \\
50 \mathrm{~mm} \text { X } 72 \mathrm{~mm} \text { X } 12 \mathrm{Mm} \\
\text { maka akan mengambil Oil } \\
\text { Seal } 55 \text { X } 72 \text { X } 9\end{array}$ & $40,20 \%$ & 5,95 \\
\hline.. & $\cdots$ & $\ldots$ & $\ldots$ \\
\hline 29 & $\begin{array}{l}\text { Jika Mengambil Oil Seal 1- } \\
\text { Lip Metal Case maka akan } \\
\text { mengambil Oil Seall 2-Lip } \\
\text { Rubber Case }\end{array}$ & $70,91 \%$ & 23,68 \\
\hline 30 & $\begin{array}{l}\text { Jika Mengambil Oil Seall 2- } \\
\text { Lip Rubber Case maka akan } \\
\text { mengambil Oil Seall 1-Lip } \\
\text { Metal Case }\end{array}$ & $90,70 \%$ & 23,68 \\
\hline
\end{tabular}

\begin{tabular}{|c|l|c|c|}
\hline 31 & $\begin{array}{l}\text { Jika Mengambil Cylindrical } \\
\text { Roller Bearing maka akan } \\
\text { mengambil Reducing Picces }\end{array}$ & $56,25 \%$ & 11,22 \\
\hline 32 & $\begin{array}{l}\text { Jika Mengambil Reducing } \\
\text { Picces maka akan } \\
\text { mengambil Cylindrical } \\
\text { Roller Bearing }\end{array}$ & $50,00 \%$ & 11,22 \\
\hline$\ldots$ & $\ldots$ & $\ldots$ & $\ldots$ \\
\hline 41 & $\begin{array}{l}\text { Jika Mengambil Obeng } \\
\text { maka akan mengambil Mur } \\
\text { Baut Metric M 12 X 50 }\end{array}$ & $46,75 \%$ & 6,85 \\
\hline 42 & $\begin{array}{l}\text { Jika Mengambil Screw 1/8" } \\
\text { X 1" maka akan mengambil } \\
\text { Baut Cis 3/16" X 1 1/2" }\end{array}$ & $46,84 \%$ & 6,73 \\
\hline
\end{tabular}

d) Pengujian Penentuan Lokasi Barang Berdasarkan Nilai LR

Berdasarkan nilai LR diperoleh 30 barang yang sering diambil oleh petugas gudang sesuai permintaan. Pada gudang yang terdiri atas 12 rak yang diberi kode rak A sampai dengan L memiliki jarak beragam dari meja petugas gudang dimana rak A adalah rak terdekat. Berdasarkan nilai LR, barangbarang telah ditata ulang sebagaimana diperlihatkan pada Tabel 7 dengan referensi lokasi rak awal barang dari meja petugas gudang pada Tabel 8. Dalam hal ini hanya diberikan contoh 10 barang. Dari Tabel 7 dapat diperoleh hasil bahwa penataan ulang barang secara umum telah mampu mereduksi jarak dan waktu pengambilan barang masing-masing sebesar $77 \%$ dan $79 \%$.

Tabel 7 Penataan Ulang Lokasi Barang Berdasarkan Nilai LR

\begin{tabular}{|c|c|c|c|c|}
\hline Nama Barang & \begin{tabular}{|c|} 
Lokasi \\
Awal \\
\end{tabular} & $\begin{array}{l}\text { Lokasi } \\
\text { Akhir }\end{array}$ & $\begin{array}{c}\text { Hemat } \\
\text { Jarak }\end{array}$ & $\begin{array}{l}\text { Hemat } \\
\text { Waktu }\end{array}$ \\
\hline $\begin{array}{l}\text { Oil Seall 2-Lip } \\
\text { Rubber Case }\end{array}$ & Rak J & Rak A & $87 \%$ & $84 \%$ \\
\hline $\begin{array}{l}\text { Oil Seall 1-Lip } \\
\text { Metal Case }\end{array}$ & Rak F & Rak A & $81 \%$ & $88 \%$ \\
\hline Kain Spon & Rak I & Rak A & $87 \%$ & $92 \%$ \\
\hline Kain Blaco & Rak I & Rak A & $87 \%$ & $92 \%$ \\
\hline \begin{tabular}{|l|} 
Reducing \\
Picces
\end{tabular} & Rak J & Rak A & $87 \%$ & $84 \%$ \\
\hline \begin{tabular}{|l|} 
Cylindrical \\
Roller Bearing
\end{tabular} & Rak G & Rak A & $82 \%$ & $90 \%$ \\
\hline Cutter & Rak I & Rak A & $87 \%$ & $92 \%$ \\
\hline $\begin{array}{l}\text { Mur Baut 1/4" } \\
\text { X 3/4" }\end{array}$ & Rak J & Rak A & $87 \%$ & $84 \%$ \\
\hline $\begin{array}{l}\text { Welding Apron } \\
\text { Leather } \\
\end{array}$ & Rak F & Rak A & $81 \%$ & $88 \%$ \\
\hline Mono Seal & Rak A & Rak A & $0 \%$ & $0 \%$ \\
\hline \multicolumn{3}{|c|}{ Nilai Rata-Rata } & $77 \%$ & $79 \%$ \\
\hline
\end{tabular}

Tabel 8 merangkum data jarak setiap rak barang A sampai dengan L dari meja petugas gudang beserta waktu yang dibutuhkan untuk mencapai rak-rak tersebut. Jarak rak-rak barang dan waktu tempuh menuju rak-rak tersebut dari meja petugas gudang diperoleh dari hasil simulasi dengan menggunakan data acak (random) menggunakan fasilitas yang 
diberikan oleh situs layanan untuk randomisasi, RANDOM.ORG, https://www.random.org/.

Tabel 8 Data Jarak Rak dari Meja Petugas Gudang

\begin{tabular}{|l|c|c|}
\hline \multicolumn{1}{|c|}{ Kode Rak } & Jarak & Waktu \\
\hline Rak A & 6 Meter & 1 Menit \\
\hline Rak B & 9 Meter & 2 Menit \\
\hline Rak C & 18 Meter & 3 Menit \\
\hline Rak D & 21 Meter & 4 Menit \\
\hline Rak E & 22 Meter & 8 Menit \\
\hline Rak F & 33 Meter & 9 Menit \\
\hline Rak G & 35 Meter & 10 Menit \\
\hline Rak H & 39 Meter & 11 Menit \\
\hline Rak I & 47 Meter & 13 Menit \\
\hline Rak J & 48 Meter & 14 Menit \\
\hline Rak K & 49 Meter & 15 Menit \\
\hline Rak L & 56 Meter & 16 Menit \\
\hline
\end{tabular}

\subsection{Analisa}

Pengasosiasian satu jenis barang dengan jenis barang lainnya pada beberapa kasus cukup menggunakan satu parameter yakni support, Badrul (2016), Nanda (2017). Namun pada umumnya menggunakan dua parameter yakni support dan confidence, Santoso (2017), Sutrisno (2020). Dalam penelitian ini, penentuan lokasi barang tidak hanya menggunakan parameter support dan confidence, namun diperkuat oleh parameter LR yang menjamin kekuatan aturan asosiasi. Maka dibandingkan dengan teknik penentuan lokasi barang dalam Nanda (2017), penentuan lokasi barang dalam penelitian ini lebih presisi dan mampu menghemat waktu dalam pengambilan barang-barang dalam gudang material.

\section{Kesimpulan}

Berdasarkan hasil-hasil penelitian di atas, dapat ditarik kesimpulan bahwa algoritma apriori mampu mempercepat dan mempermudah akses barangbarang di gudang material melalui penataan ulang barang berdasarkan kombinasi nilai minimum support, minimum confidence, dan LR yang tepat. Penataan ulang lokasi barang-barang berdasarkan nilai LR mampu memberikan peningkatan kinerja petugas gudang khususnya pada aspek waktu.

Di sisi lain, kombinasi antara nilai minimum support dan nilai minimum confidence memberi pengaruh signifikan pada pembentukan aturan asosiasi pada frequent itemset. Semakin kecil kedua nilai tersebut maka semakin banyak aturan asosiasi yang dibentuk sehingga dapat meningkatkan ketepatan pengambilan barang sesuai dengan permintaan.

\section{Daftar Pustaka}

Aristanto, I. G. (2017). Perancangan Tata Letak Gudang Pada UD Diamond Jaya di
Surabaya. Calyptra: Jurnal Ilmiah Mahasiswa Universitas Surabaya, 921-939.

Badrul, M. (2016). Algoritma Asosiasi Dengan Algoritma Apriori Untuk Analisa Data Penjualan. Jurnal Pilar Nusa Mandiri, 127.

Buulolo, E. (2013). Implementasi Algoritma Apriori Pada Sistem Persediaan Obat (Studi Kasus : Apotik Rumah Sakit Estomihi Medan). Pelita Informatika Budi Darma, 80-81.

Han, J., Kamber, M., \& Pei, J. (2013). Data Mining. Concepts and Techniques, 3rd Edition. Waltham: Morgan Kaufmann Publishers.

Mandave, P., Mane, M., \& Patil, S. (2013). Data Mining using Association Rule-based on Apriori Algorithm and Improved Approach with Illustration. International Journal of Latest Trends in Engineering and Technology (IJLTET), 107-113.

Nanda, M., \& Saleh, K. (2017). Aplikasi Penataan Letak Barang di Imam Market dengan Metode Apriori. Jusikom Prima, 1-5.

Rahardjo, B. (2017). Perancangan Sistem Manajemen Gudang Material. Jurnal Teknik Industri, 127-136.

Riszky, A.R., \& Sadikin, M. (2019). Data Mining Menggunakan Algoritma Apriori untuk Rekomendasi Produk bagi Pelanggan. Jurnal Teknologi dan Sistem Komputer, 103-108.

Santoso, H. (2017). Data Mining Penyusunan Buku Perpustakaan Daerah Lombok Barat Menggunakan Algoritma Apriori. Seminar Nasional TIK dan Ilmu Sosial (SocioTech) 2017 (hal. 25-35). STMIK Bumigora.

Singh, R., \& Chaudhary, S. (2012). Data Mining Approach Using Apriori Algorithm: The Review. IOSR Journal of Electronics and Communication Engineering (IOSR-JECE), 12-15.

Sutrisno. (2020). Penerapan Algoritma Apriori Untuk Mencari Pola Penjualan Produk Dana Pada PT Bank Rakyat Indonesia (Persero) Tbk Kanca Jakarta Pasar Minggu. Jurnal SIMIKA, 18.

What's this fuss about true randomness? (2020, 623$)$. Diambil kembali dari RANDOM.ORG: https://www.random.org/

Yuliana, W., Budiawan Z, W., Taufik, I., \& Manaf, K. (2018). Implementasi Algoritma Apriori untuk Mengoptimalkan Kombinasi Menu di Kane Pizzeria Bandung. Insight, 195-201.

Zahrotun, L., Setiadi, T., \& Haryadi, T. M. (2018). Aplikasi Data Mining untuk Mencari Pola Asosiasi Tracer Study Menggunakan Algoritma FOLDARM. Jurnal Nasional Teknologi dan Sistem Informasi, 38-43. 
Volume 7, Edisi 2, Februari 2021

$\mathbf{2 8} \mid \mathrm{H}$ a 1 a $\mathrm{m}$ a $n$ 